\title{
Erratum to: Use of natural products in the crop protection industry
}

\author{
Ottmar Franz Hüter
}

Published online: 1 September 2010

(C) Springer Science+Business Media B.V. 2010

\section{Erratum to: Phytochem Rev DOI 10.1007/s11101-010-9168-y}

Unfortunately, wrong version of Fig. 10 has been mistakenly published in the original article. The correct version is given below.

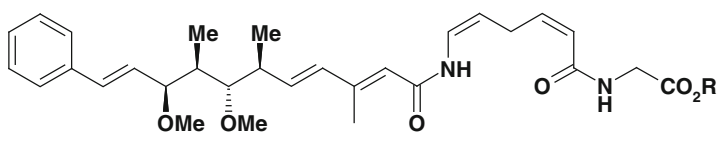

$29 \mathrm{R}=\mathrm{Me}$ Crocacin $\mathrm{A}$

$30 \quad \mathrm{R}=\mathrm{H} \quad$ Crocacin $\mathrm{B}$<smiles>CO[C@H](/C=C/c1ccccc1)C(C)C(C)C(C)/C=C/C(C)=C/C(N)=O</smiles>

31 Crocacin C<smiles>COC(/C=C/c1ccccc1)C(C)C(C)C(C)/C=C/C(C)=C/C(=O)N/C=C\CCCC(=O)NCC(C)=O</smiles>

32 Crocacin D

Fig. 10 Structures of the crocacins 